\title{
ANXIETY ASSOCIATED WITH ORAL HEALTH AMONG ADOLESCENTS
}

Dr. Khaled Hassan', Asala Wafa ${ }^{2}$, Doha Abafallata ${ }^{2}$, Hatun Aletayani ${ }^{3}$, Ali Mohammed Alshehri ${ }^{4}$, Nuha Abdulaziz Alharbi ${ }^{5}$, Sultan Alluqmani ${ }^{5}$, Abdullah Khalid W Alharbi ${ }^{6}$, Areej Maqnss ${ }^{6}$, Abdulrahman Alsani ${ }^{6}$, Mohammed Khawaji ${ }^{7}$, Mohammed Alraqibah $^{8}$, Abdullah owaidh Alotaibi ${ }^{9}$, Fatimah Al-Hamar ${ }^{10}$, Salwa Majrashi' ${ }^{11}$, Ali Aleid ${ }^{12}$, Yousef Hamoud Almutairi ${ }^{13}$, Mishary Alkhurim $^{14}$

\author{
${ }^{1}$ Consultant Family Medicine, Saudi Arabia. \\ ${ }^{2}$ Batterjee Medical College, Saudi Arabia. \\ ${ }^{3}$ Vision Colleges, Saudi Arabia. \\ ${ }^{4}$ King Khalid University, Saudi Arabia. \\ ${ }^{5}$ King Abdulaziz University, Saudi Arabia. \\ ${ }^{6}$ Taibah University, Saudi Arabia. \\ ${ }^{7}$ King Saud University, Saudi Arabia. \\ ${ }^{8}$ Qassim University, Saudi Arabia. \\ ${ }^{9}$ Taif University, Saudi Arabia. \\ ${ }^{10}$ King Faisal University, Saudi Arabia. \\ ${ }^{11}$ Jazan University, Saudi Arabia. \\ ${ }^{12}$ Medical University of Lodz, Poland. \\ ${ }^{13}$ Dar Al Uloom, Saudi Arabia. \\ ${ }^{14}$ Najran University, Saudi Arabia.
}

Article Info: Received 20 July 2021; Accepted 21 August 2021

DOI: https://doi.org/10.32553/ijmbs.v5i9.2185

Corresponding author: Dr. Khaled Hassan

Conflict of interest: No conflict of interest.

\begin{abstract}
Background: A Psychological discomfort can influence how people behave when it comes to their health. We looked at how gender, school grade, parents' education, family structure, smoking, and perceived overall health influenced psychological distress, social phobia (SP), and anxiety linked with dental brushing among Finnish teenagers.

Methodology: This research is part of the national School Health Promotion Study in Finland (SHP). A representative sample of Finnish 15-year-olds $(\mathrm{N}=45,877)$ was used in the study. SP and anxiety were assessed using the Mini-Social Phobia Inventory (Mini-SPIN) and generalized anxiety disorder (GAD). The respondents' oral health behaviors (tooth brushing, smoking), background characteristics (age, gender, family structure, and parents' education), and perceived general health were all asked about in a questionnaire. In the study, Chi-squared tests and logistic regression analyses were used.
\end{abstract}

Keywords: Adolescents, Oral health behaviour, Psychological distress, Tooth brushing.

\section{Introduction}

Dental health is a crucial component of overall health, and oral problems are linked to chronic illnesses including diabetes and cardiovascular disease $[1,2]$. Oral and general health risk factors have been found to be quite important in integrating oral and general health [3]. The theories explaining oral health inequities have been merged into one conceptual framework (CF) [3], and the common risk factor approach has been connected into a social determinants framework. Te CF outlines how structural and intermediary determinants, such as material, behavioral, cultural, and psychosocial determinants, affect oral health through social determinates [3, 4]. Adolescence is a time of many psychological, social, and physical changes. Anxiety and social phobia (SP) can affect a young person's capacity to cope and negatively impact one's quality of life as the necessity for autonomous functioning develops in adolescence [5, 6]. Anxiety and SP symptoms commonly appear in late childhood or adolescence [7]. Girls are more likely than boys to experience psychological distress [8, 9]. The Mini-Social Phobia Inventory (Mini-SPIN) can be used to identify SP in teenagers [7], and the GAD-7 questionnaire can be used to assess Generalized Anxiety Disorder (GAD), one of the most frequent mental disorders [10]. At a young age, the foundation for oral health behaviors and practices is formed. There are numerous changes throughout the transition from infancy to adulthood [13]. During this time, children's independence from their parents grows, resulting in behavioural changes such as food habits, smoking, health behavior, and lifestyle behavior $[13,14]$. . The development of these independent behaviors can have an impact on dental health and set life-long behavioral habits [13]. Young people who take care of their teeth are more likely to take care of other aspects of their health $[15,16]$. Brushing one's teeth is the most effective oral hygiene procedure, and brushing twice day is universally advised [17]. Girls clean their teeth more often than boys, indicating a gender difference in tooth 
brushing among teenagers $[15,16,18-20]$. High parental employment level and household afuence have been linked to a higher prevalence of tooth brushing more than thrice a day among early adolescents [19]. Smoking has also been linked to a negative association with socioeconomic status and a strong link with infrequent tooth brushing behaviors among adolescents [18, 21]. Children from two-parent families had a higher incidence of cleaning their teeth more than once a day [19]. Studies have found links between psychological discomfort and dental health in adults, such as the link between depression and anxiety and less frequent teeth brushing [22]. as well as the link between stress and depressed symptoms and poor dental health [22-24]. Teenagers with psychological distress clean their teeth twice a day less frequently than adolescents with good mental health, according to studies conducted outside of Europe [25]. In adolescence, a link between periodontitis and dimensions of psychosocial distress has been established [26], and poor maternal variables (e.g., low education, and psychological anguish) can have a cumulative impact on adolescents' future caries experiences [27]. There is little evidence of how psychological distress affects teenage oral health behavior. The goal of this study was to see if there was a link between tooth brushing and psychological distress in Finnish teenagers while adjusting for gender, Parental education, family structure, smoking, and overall health perception We hypothesized that those who were more depressed would clean their teeth twice a day less frequently than people who were less depressed.

\section{Material and Methods}

\section{Participants and Study Design}

This study makes use of data from the Finnish School Health Promotion Study (SHP), which tracks the health, health behaviors, well-being, and schooling of 14 to 20 -year-olds in Finland. Every two years, the SHP research is conducted across the country. Pupils in their eighth and ninth years of comprehensive school in mainland Finland and the land Islands are among the respondents, accounting for 80 percent of the target group in Finland. [28]. Every municipality in Finland receives the survey and determines whether or not to send it to the schools in their region [29]. The study was authorized by Finland's National Institute for Health and Welfare's Ethics Committee. The study's participation was entirely optional, and students agreed to take part by filling out a survey. In April 2013, data were obtained via an anonymous, voluntary questionnaire administered in the classroom under the supervision of a teacher [28]. Comprehensive education in Finland lasts nine years, from the ages of seven to sixteen. In 2013, the SHP study drew participants from all throughout the country, with an 84 percent participation rate among teenagers in comprehensive school grades eight and nine [15]. We collected data from 45,877 15-year-olds (excluding 830 participants who failed to indicate their tooth brushing frequency) who were in their eighth $(37 \%)$ or ninth $(63 \%)$ year of comprehensive school in the spring of 2013 for this cross-sectional study. Males made up $49.9 \%$ of the participants in our study.

\section{Statistical Analysis}

For categorical data, the Pearson's chi-squared test (2) was used, and for continuous data, the analysis of variance test was used. To establish the independence of discovered components, a binary logistic regression was performed (OR). Cohen's k coefficient, Spearman's correlation coefficient, and $\mathrm{R}$ square were used to express the relationship and concordance between ACT/GINA regarding asthma control (R2). SPSS 20.0 was used to analyze all of the data [35-40].

\section{Results}

\section{Demographics and Clinical Characterization}

Table (1) shows the frequency of tooth brushing among 15year-old Finns based on various parameters. Only almost two-thirds of the girls (66.7\%) and less than half of the boys (40.1\%) followed the international advice of brushing their teeth twice a day. . Adolescents with parents who had only a basic education washed their teeth twice a day less frequently than adolescents with parents who had a secondary or tertiary degree. Adolescents who lived with both parents also washed their teeth twice as often as those who lived in other family arrangements. Nonsmokers washed their teeth twice a day more frequently than smokers.

Table 1: Tooth brushing frequency among Finnish 15-year-olds $(\%, n)$ by their chracteriatics

\begin{tabular}{|c|c|c|c|}
\hline \multicolumn{4}{|c|}{ Footh boresth } \\
\hline & 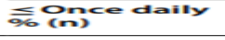 & 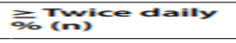 & 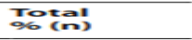 \\
\hline $\begin{array}{l}\text { Gender } \\
\text { Boys }\end{array}$ & $590(13,714)$ & $40.1(917)$ & $100(22,891)$ \\
\hline $\begin{array}{l}\text { Sirns } \\
\text { all }\end{array}$ & $\begin{array}{l}332(7645) \\
460(21.359)\end{array}$ & $\begin{array}{l}66.7(15,341) \\
53.4(24,518)\end{array}$ & $100(22,808)$ \\
\hline $\begin{array}{l}\text { sum grade } \\
\text { sing grade }\end{array}$ & $\begin{array}{l}48.1(\cos 149) \\
45,(13,210)\end{array}$ & $\begin{array}{l}\text { si.9 (8sa) } \\
54.3 \text { (15.710) }\end{array}$ & $\begin{array}{l}100 \times 10,957 \\
100(28,920)\end{array}$ \\
\hline 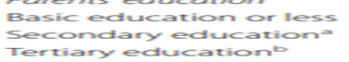 & $\begin{array}{l}562(1498) \\
498(10,24) \\
409(1900)\end{array}$ & $\begin{array}{l}43.8(1100) \\
502(10.3100 \\
59-141.509\end{array}$ & $\begin{array}{l}100(2004) \\
100(2054) \\
100 .(1947)\end{array}$ \\
\hline $\begin{array}{l}\text { Faming structure } \\
\text { With both parcerts } \\
\text { Other }\end{array}$ & $\begin{array}{l}444(13,565) \\
508(1322)\end{array}$ & $\begin{array}{l}55.6(17-013) \\
492(1092)\end{array}$ & $100(30,583)$ \\
\hline $\begin{array}{l}\text { Wurreme smakcimg habirs } \\
\text { Dally or accasional } \\
\text { Nom-smoker }\end{array}$ & $\begin{array}{l}542(03)(2) \\
43.9(14.601)\end{array}$ & $\begin{array}{l}45.8(5387) \\
\text { 56.1 (18.796) }\end{array}$ & $100(11,759)$ \\
\hline 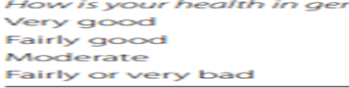 & 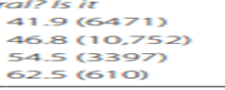 & $\begin{array}{l}58.1(8984) \\
53.2(12.201) \\
45.5(2838) \\
375(368) \\
3750\end{array}$ & $\begin{array}{l}100(15,455) \\
100 \cdot(22,953) \\
100(6235) \\
100(6>6)\end{array}$ \\
\hline & & & \\
\hline
\end{tabular}


Figures 1 and 2 shows the aggregate scores of the Mini-SPIN and GAD-7 questionnaires among Finnish 15-year-olds. Females were more likely than boys to express possible difficulties with SP and GAD: 25.4 percent of girls and 14.0 percent of boys had Mini-SPIN scores core 6 or higher, indicating possible SP. In terms of GAD-7, $16.6 \%$ of the girls and 6.0 percent of the boys had a cumulative score of 10 or above, indicating the possibility of GAD. There was a 0.4 association between the three Mini-SPIN items and the seven GAD-7 items. The item 'Being embarrassed or looking dumb are among my worst worries' was the most often reported Mini-SPIN item, with nearly one in four girls $(19.1 \%)$ and one in ten boys $(10.1 \%)$ answering 'Very much' or 'Extremely' (data not presented). The GAD-7's most frequently reported item 'Becoming easily agitated or irritable' was the topic of the survey. With nearly a quarter of the girls $(24.9 \%)$ and one in ten boys (10.8\%) replying "more than half of the days" or "nearly every day" for this question (data not presented). Tose boys and girls (Table 2) who had probable SP problems washed their teeth at least twice a day less frequently than those who had no possible SP problems.
Seven out of ten males and four out of ten girls said they only washed their teeth once a day or less. Additionally, those with moderate or severe anxiety (GAD-7 score 10) brushed their teeth less frequently than those with minimal, minor, or mild anxiety (GAD-7 score 9). Boys were more likely than girls ( $\mathrm{OR}=3.2$; 95 percent $\mathrm{CI}$ 3.1-3.4) not to wash their teeth twice daily, according to logistic regression analysis (Table $3)$. Adolescents with parents with only a basic education $(\mathrm{OR}=1.5$; CI 95 percent $1.4-1.5)$ were likewise more likely than those with parents with a secondary or tertiary education not to wash their teeth twice daily (OR=1.5; CI 95 percent 1.4-1.5). Adolescents with a good or very good perception of their current health brushed their teeth twice as often as those with a middling, pretty, or very terrible perception of their current health. Boys $(\mathrm{OR}=1.3 ; 95$ percent CI 1.2-1.5) and girls $(\mathrm{OR}=1.4$; 95 percent $\mathrm{CI} 1.4-1.5)$ were less likely than those not reporting possible problems with SP to clean their teeth twice daily, according to gender-specific logistic regression analyses (Table 4). Smokers were less likely than non-smokers to clean their teeth twice daily, especially among boys ( $\mathrm{OR}=1.7$; 95 percent $\mathrm{CI} 1.6-1.8)$.

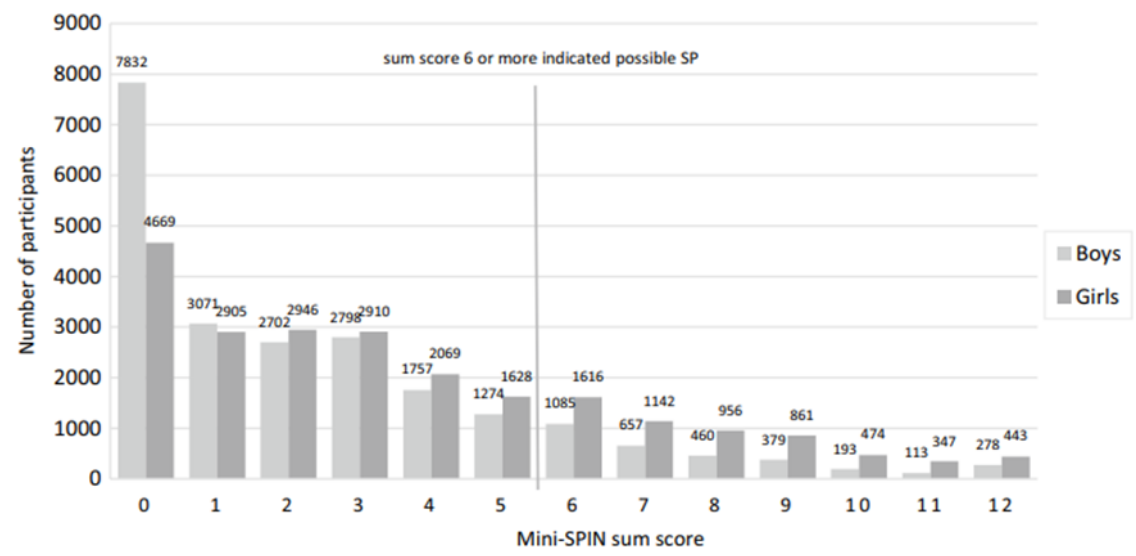

Figure 1: The number of participants according to the mini-SPIN sum score

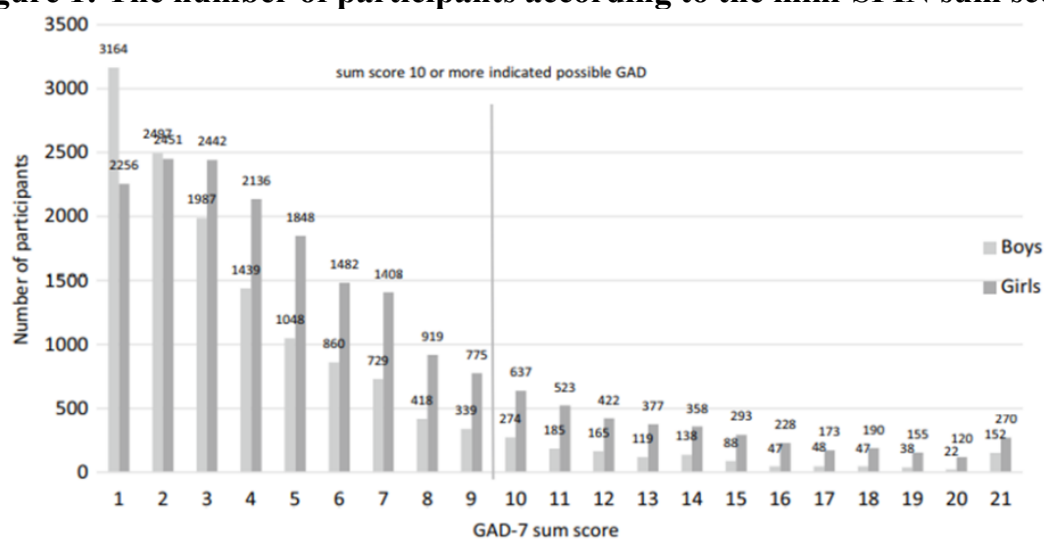

Figure 2: The number of participants according to GAD-7 sum score

Also those with poor perceived general health were less likely to clean their teeth twice daily than those with moderate or good perceived general health: girls $(\mathrm{OR}=1.9 ; 95$ percent $\mathrm{CI}$ 1.6-2.2) and boys $(\mathrm{OR}=1.6$; 95 percent CI 1.2-2.1). GAD-7-based gender-specific logistic regression studies revealed an increase in their motivation to wash their teeth on a regular basis. Adolescents who have problems with SP are more likely to have dental health problems. 
Table 2: Tooth brushing frequency among Finnish 15-year-olds boys and girls to Mini -SPIN and GAD-7classification

\begin{tabular}{|c|c|c|c|}
\hline & \multicolumn{3}{|c|}{ Tooth brushing } \\
\hline & $\begin{array}{l}\text { SOnce daily } \\
\%(n)\end{array}$ & $\begin{array}{l}\geq \text { Twice daily } \\
\%(n)\end{array}$ & $\begin{array}{l}\text { Total } \\
\%(n)\end{array}$ \\
\hline \multicolumn{4}{|l|}{ Boys } \\
\hline \multicolumn{4}{|l|}{ Mini-SPIN classification } \\
\hline $0-5$ points (No SP) & $58.8(11,175)$ & $41.2(7828)$ & $100(19.003)$ \\
\hline 6-12 points (Possible SP) & $66.4(2059)$ & $33.6(1043)$ & $100(3102)$ \\
\hline Total & $59.9(13.234)$ & $40.1(8871)$ & $100(22,105)$ \\
\hline \multicolumn{4}{|l|}{ GAD-7, 2 categories } \\
\hline o-9 points (No, slight or mild anxiety) & $59.2(11.937)$ & $40.8(8230)$ & $100(20,167)$ \\
\hline 10-21 points (Moderate to severe anxiety) & $68.2(876)$ & $31.8(408)$ & $100(1284)$ \\
\hline Total & $59.7(12,813)$ & $40.3(8638)$ & $100(21,451)$ \\
\hline \multicolumn{4}{|l|}{ Girls } \\
\hline \multicolumn{4}{|l|}{ Mini-SPIN classification } \\
\hline 0-5 points & $31.1(5267)$ & $68.9(11,677)$ & $100(16,944)$ \\
\hline 6-12 points & $39.6(2286)$ & $60.4(3492)$ & $100(5778)$ \\
\hline Total & $33.2(7553)$ & $66.8(15,169)$ & $100(22,722)$ \\
\hline \multicolumn{4}{|l|}{ GAD-7, 2 categories } \\
\hline 0-9 points & 31.9 (5955) & $68.1(12,691)$ & $100(18,646)$ \\
\hline $10-21$ points & $39.6(1462)$ & $60.4(2229)$ & $100(3691)$ \\
\hline Total & $33.2(7417)$ & $66.8(14,920)$ & $100(22,337)$ \\
\hline
\end{tabular}

Table 3: Results of logistic regression analyses tooth brushing $(n=45,877)$ as dependent variable.

\begin{tabular}{|c|c|c|}
\hline & OR & $95 \% \mathrm{Cl}$ \\
\hline \multicolumn{3}{|l|}{ Sex } \\
\hline Girl & 1.0 & \\
\hline Boy & $3.2^{*}$ & $(3.1-3.4)$ \\
\hline \multicolumn{3}{|l|}{ Mini-SPIN } \\
\hline $0-5$ points (No SP) & 1.0 & \\
\hline 6-12 points (Possible SP) & $1.4^{*}$ & $(1.3-1.4)$ \\
\hline \multicolumn{3}{|l|}{ Parents' education } \\
\hline Secondary or tertiary education & 1.0 & \\
\hline Basic education or less & $1.5^{*}$ & $(1.4-1.5)$ \\
\hline \multicolumn{3}{|l|}{ Fomily structure } \\
\hline With both parents & 1.0 & \\
\hline Other & $1.2^{*}$ & $(1.2-1.3)$ \\
\hline \multicolumn{3}{|l|}{ Smoking } \\
\hline Non-smoker & 1.0 & \\
\hline Daily or occasional & $1.5^{*}$ & $(1.4-1.5)$ \\
\hline \multicolumn{3}{|l|}{ How is your health in general? Is it } \\
\hline Very good, fairly good or moderate & 1.0 & \\
\hline Fairly or very bad & $1.8^{*}$ & $(1.5-2.0)$ \\
\hline
\end{tabular}

Table 4: Gender specific results of logistic regression analyses including Mini-SPIN tooth brushing (n=45,877) as dependent variable

\begin{tabular}{|c|c|c|c|c|}
\hline & \multicolumn{2}{|c|}{ Boys } & \multicolumn{2}{|c|}{ Girls } \\
\hline & OR & $9596 \mathrm{Cl}$ & OR & $9596 \mathrm{Cl}$ \\
\hline \multicolumn{5}{|l|}{ Mini-SPIN } \\
\hline 0-5 points (No SP) & 1.0 & & 1.0 & \\
\hline 6-12 points (Possible SP) & $1.3^{-}$ & $(1.2-1.5)$ & $1.4^{-}$ & $(1.3-1.5)$ \\
\hline \multicolumn{5}{|l|}{ Parenrs educarion } \\
\hline Secondary or tertiary education & 1.0 & & 1.0 & \\
\hline Basic education or less & $1.5{ }^{-}$ & $(1.4-1.6)$ & $1.5-$ & $(1.4-1.6)$ \\
\hline \multicolumn{5}{|l|}{ Family structure } \\
\hline With both parents & 1.0 & & 1.0 & \\
\hline Other & $1.2^{-}$ & $(1.2-1.3)$ & $12^{-}$ & $(1.2-1.3)$ \\
\hline \multicolumn{5}{|l|}{ Smoking } \\
\hline Non-smoker & 1.0 & & 1.0 & \\
\hline Daily or occasional & $1.7 \times$ & $(1.6-1.8)$ & $13^{-}$ & $(1.2-1.3)$ \\
\hline \multicolumn{5}{|l|}{ How is your health in general? is it } \\
\hline Very good, fairly good or moderate & 1.0 & & 1.0 & \\
\hline Fairly or very bad & $1.6^{-}$ & $(1.2-2.1)$ & $1.9^{-}$ & $(1.6-2.2)$ \\
\hline
\end{tabular}


Table 5: Gender specific results of logistic regression analyses including GAD-7 tooth brushing $(n=45,877)$ as dependent variable

\begin{tabular}{|c|c|c|c|c|}
\hline \multicolumn{3}{|c|}{ dependent variable } & \multicolumn{2}{|c|}{ Girls } \\
\hline & OR & $9596<1$ & OR & $9596<1$ \\
\hline \multicolumn{5}{|l|}{ GAD-> } \\
\hline O-9 points (No, slight or mild anxiety) & 1.0 & & 1.0 & \\
\hline $\begin{array}{l}10-21 \text { points (Maderate to severe anxi- } \\
\text { ety) }\end{array}$ & $1.2=$ & $(1-1-1-4)$ & $1.2-$ & $(1-1-1-3)$ \\
\hline \multicolumn{5}{|l|}{ Parents edication } \\
\hline Secondary or tertiary education & 1.0 & & 1 . 0 & \\
\hline Basic education or lless & $1.5-$ & $(1.4-1.6)$ & $15=$ & $(14-1-6)$ \\
\hline \multicolumn{5}{|l|}{ Family simucture } \\
\hline With both parents & 1.0 & & 1.0 & \\
\hline Other & $1.3 \infty$ & $(1,2-1-3)$ & $12=$ & $(1-2-1+3)$ \\
\hline \multicolumn{5}{|l|}{ Smaking } \\
\hline Non-smoker & 1.0 & & 1 - 0 & \\
\hline Dailly or accasional & $1 .>\infty$ & $(1,6-1,8)$ & $12=$ & $(1-1-1-3)$ \\
\hline \multicolumn{5}{|l|}{ How is yaur heavith in generall is it } \\
\hline Very good, fairly gaod or maderate & 1.0 & & 1.0 & \\
\hline Fairly or very bad & $1 .>\infty$ & $(1-3-23)$ & 19 & $(1.5-2.2)$ \\
\hline
\end{tabular}

\section{Discussion}

Adolescents in Finland experience psychological distress as a result of brushing their teeth. Tose who reported possible SP problems or moderate to severe possible general anxiety brushed their teeth twice a day less frequently than those who reported no possible SP problems or minimal or low general anxiety. Although there was no substantial link between tooth brushing and psychological discomfort, the difference between those who had possible psychological distress and those who did not wash their teeth twice daily varied between $7.6 \%$ and $9 \%$, which is clinically significant. Our findings corroborate those of earlier adolescent research in Asia, Africa, the Caribbean, and South America [25]. The difficulties that cause psychological discomfort can take up an adolescent's focus to the point that they are unable to follow the recommended oral health practices. The social benefits of clean teeth (together with caries prevention) are the key considerations that encourage tooth brushing [31]. Clean teeth seem appealing, provide a sensation of freshness, and increase one's self-confidence. Adolescents may be more aware of the social benefits of teeth brushing if they have less social issues. The incidence of twice-daily tooth brushing was low, particularly among Finnish boys. However, there has been some progress in teeth brushing: in 2001-2002, 45 percent of Finnish 15-year-olds brushed according to the recommendation; in our survey, the comparable figure was 53 percent [32]. Girls reported suspected SP and anxiety more frequently than boys in our study, as in earlier investigations $[8,9]$. Due to psychological anguish, more frequent problems with SP in girls may have poor oral health consequences. Girls, on the other hand, reported brushing their teeth twice as often as boys, providing them with more protection against oral health concerns. Other factors, in addition to psychological distress, may influence the frequency with which females wash their teeth. For example, girls may value clean, attractive teeth and oral health more than boys, which could improve their mood and raise their drive to brush their teeth. Furthermore, women are more likely than men to engage in favourable health behaviours [33]. Adolescents with parents who only had a basic education washed their teeth twice daily less often than adolescents with parents who had a secondary or higher degree, according to this study. Previous research has also indicated that a parent's higher educational level and socioeconomic status are linked to an adolescent's brushing frequency [19, 34]. Girls, for example, may place a higher importance on clean, attractive teeth and oral health than boys, which may boost their mood and motivation to brush their teeth. In addition, women are more likely than men to engage in healthy habits [33]. According to this study, teenagers with parents who only had a basic education brushed their teeth twice daily less frequently than adolescents with parents who had a secondary or higher education. Brushing frequency is also associated to a parent's higher educational level and socioeconomic class, according to previous studies [19, 34]. . Higher parental educational levels have been linked to better psychological health and fewer health problems in children [35], which could be due to a solid socioeconomic status. Furthermore, higher family educational expectations have been linked to better health behavior, including teeth brushing [36]. The findings of this study imply that family structure affects tooth brushing; individuals who grew up in a traditional family with two parents washed their teeth twice as often as those who grew up in a different home. Previous research into the link between family structure and children's dental brushing practices has yielded mixed results in different countries [19]. Parents have a significant influence on their children's tooth brushing behaviors; regular family routines and practices that promote excellent oral health early in life are critical for children's oral health $[19,37]$. A family of two parents can achieve regular family routines more easily than, say, a family of one parent. Furthermore, social stressors such as dysfunctional family connections and home dynamics are common among socioeconomically disadvantaged teenagers, which may enhance their risk of poor oral health [37]. People who suffer from mental illnesses may have a restricted capacity for self-care and the prevention of oral diseases. Furthermore, delivering dental health treatment for patients with mental illnesses is difficult [38]. Smoking was linked to inadequate tooth brushing in this study, particularly among boys. Similar findings have 
been seen in previous investigations of boys and girls [18, 39] as well as young males [40]. . Smokers, on average, have worse oral health behaviors and oral health than nonsmokers [40]. Because smoking impairs one's sense of smell and taste, smokers may not appreciate the clean, fresh feeling that tooth brushing provides in the same way that non-smokers do; they may also regard oral health as less important than nonsmokers. Adolescents who reported good or very good perceived health brushed their teeth twice daily more often than those who reported middling, moderately, or very poor considered health, according to the findings of this study. Because tooth brushing is linked to oral health, which is linked to overall health, it's not unexpected that those who reported poor perceived health brushed their teeth less than twice daily. Only a few research have looked into the link between teeth brushing and overall health. A recent study of 71449 people found that cleaning your teeth more frequently every day reduced the risk of developing all forms of cancers [41]. In addition, because bad health habits tend to cluster together $[16,18,39]$, infrequent tooth brushing, in combination with other bad health habits and other aspects of life, may contribute to a negative perception of health. The Finnish School Health Promotion Study has a large sample size of almost $80 \%$ of Finnish 15-year-olds, with an even gender distribution, and its findings may be applied to all Finnish 15 -year-olds. Our study is similarly comparable to international surveys of adolescent oral health behavior due to its high sample size. The Finnish School Health Promotion Study provides important information about the development of adolescents' health behavior because it is conducted on a regular basis (every two years). The study's reliability and validity were improved by using validated tools to assess the participants' SP and anxiety, such as the Mini-SPIN and the GAD-7. Although self-reported outcome measures may be susceptible to socially acceptable responses, the results can be regarded credible because participants answered voluntarily and anonymously. Because this is a crosssectional study, no causal inferences should be drawn.

\section{Conclusion}

Finally, teenagers who reported possible problems with SP or general anxiety washed their teeth twice a day less frequently than those who did not indicate any possible problems with SP or general anxiety. Psychological distress is linked to an increased risk of oral health disorders as early as adolescence, and it may help to explain oral health disparities later in life.

\section{References}

1. Cullinan MP, Ford PJ, Seymour GJ. Periodontal disease and systemic health: current status. Aust Dent J. 2009;54(1):62-9.

2. Dörfer C, Benz C, Aida J, Campard G. The relationship of oral health with general health and NDCs: a brief review. Int Dent J. 2017; 67(Suppl 2):14-8.
3. Watt RG, Sheiham A. Integrating the common risk factor approach into a social determinants framework. Community Dent Oral Epidemiol. 2012; 40(4):28996.

4. Duijster D, Oude Groeniger J, van der Heijden GJMG, van Lenthe FJ. Material, behavioural, cultural and psychosocial factors in the explanation of socioeconomic inequalities in oral health. Eur J Public Health. 2018; 28(4):590-7.

5. Connor KM, Kobak KA, Churchill LE, Katzelnick D, Davidson JR. Mini-SPIN: A brief screening assessment for generalized social anxiety disorder.

6. Marsh IC, Chan SWY, MacBeth A. Self-compassion and psychological distress in adolescents - a metaanalysis. Mindfulness (N Y). 2018; 9(4):1011-27.

7. Ranta K, Kaltiala-Heino R, Rantanen P, Marttunen M. The Mini-Social Phobia Inventory: psychometric properties in an adolescent general population sample. Compr Psychiatry. 2012; 53(5):630-7.

8. Nerdrum P, Rustøen T, Rønnestad MH. Student psychological distress: a psychometric study of 1750 Norwegian 1st year undergraduate students. Scan J Educ Res. 2006; 50(1):95-109.

9. Saïas T, du Roscoät E, Véron L, Guignard R, Richard JB, Legleye S, et al. Psychological distress in French college students: demographic, economic and social stressors. Results from the 2010 National Health Barometer. BMC Public Health. 2010; 2014(14):256.

10. Remes $\mathrm{O}$, Brayne $\mathrm{C}$, van der Linde R, Lafortune L. A systematic review of reviews on the prevalence of anxiety disorders in adult populations. Brain Behav. 2016;6(7):e00497. https://doi.org/10.1002/brb3.497.

11. Spitzer RL, Kroenke K, Williams JB, Löwe B. A brief measure for assessing generalized anxiety disorder: the GAD-7. Arch Intern Med. 2006;166(10):1092-7.

12. Tiirikainen $K$, Haravuori $H$, Ranta $K$, Kaltiala-Heino R, Marttunen M. Psychometric properties of the 7item Generalized Anxiety Disorder Scale (GAD7) in a large representative sample of Finnish adolescents. Psychiatry Res. 2019;272:30-5.

13. Frech A. Healthy behavior trajectories between adolescence and young adulthood. Adv Life Course Res. 2012;17(2):59-68.

14. Tseveenjav B, Pesonen P, Virtanen JI. Use of snus, its association with smoking and alcohol consumption, and related attitudes among adolescents: the Finnish National School Health Promotion Study. Tob Induc Dis. 2015;13:34.

15. Lehtinen AE, Joronen $K$, Similä $T$, Rantanen A, Virtanen JI. School achievement and oral health behavior among adolescents in Finland: a national survey. Oral Health Prev Dent. 2020;18(2):125-32.

16. Virtanen JI, Muikku T, Similä T, Cinar AB, Pohjola V. Physical activity, BMI and oral health behaviour among adolescents: Finnish School Health Promotion Study. Eur J Public Health. 2019;29(2):296-302.

17. Löe $\mathrm{H}$. Oral hygiene in the prevention of caries and periodontal disease. Int Dent J. 2000;50(3):129-39. 
18. Honkala S, Honkala E, Newton $\mathrm{T}$, Rimpelä A. Toothbrushing and smoking among adolescentsaggregation of health damaging behaviours. J Clin Peridontol. 2011;38(5):442-8.

19. Maes L, Vereecken C, Vanobbergen J, Honkala S. Tooth brushing and social characteristics of families in 32 countries. Int Dent J. 2006;56(3):159-67.

20. Marques-Vidal P, Milagre V. Are oral health status and care associated with anxiety and depression? A study of Portuguese health science students. J Public Health Dent. 2006;66(1):64-6.

21. Koivusilta LK, West $P$, Saaristo VM, Nummi T, Rimpelä AH. From childhood socio-economic position to adult educational level - do health behaviours in adolescence matter? A longitudinal study. BMC Public Health. 2013;13:711.

22. Anttila S, Knuuttila M, Ylöstalo $P$, Joukamaa M. Symptoms of depression and anxiety in relation to dental health behavior and self-perceived dental treatment need. Eur J Oral Sci. 2006;114(2):109-14.

23. Deinzer R, Hilpert D, Bach K, Schawacht M, Herforth A. Efects of academic stress on oral hygiene-a potential link between stress and plaque associated disease? J Clin Periodontol. 2001;28(5):459-64.

24. Finlayson TL, Williams DR, Siefert K, Jackson JS, Nowjack-Raymer R. Oral health disparities and psychosocial correlates of self-rated oral health in the National Survey of American Life. Am J Public Health. 2010;100(Suppl 1):S246-55.

25. Peltzer K, Pengpid S. Oral health behaviour and social and health factors in university students from 26 low, middle and high income countries. Int J Environ Res Public Health. 2014;11(12):12247-60.Depress Anxiety. 2001;14(2):137-40.

26. López $\mathrm{R}$, Ramírez $\mathrm{V}$, Marró $\mathrm{P}$, Baelum $\mathrm{V}$. Psychosocial distress and periodontitis in adolescents. Oral Health Prev Dent. 2012;10(3):211-8.

27. Nelson S, Lee W, Albert JM, Singer LT. Early maternal psychosocial factors are predictors for adolescent caries. J Dent Res. 2012;91(9):859-64.

28. Matikka A, Luopa P, Kivimäki H, Jokela J, Paananen $\mathrm{R}$. The well-being of eight-year and ninth-year pupils with an immigrant background. School Health Promotion Study 2013. Discussion paper 6/2015. National Institute for Health and Welfare (THL). 2015.

http://www.julkari.f/bitstream/handle/10024/125546/ URN_ISBN_978-952-302-4342.pdf?sequence $=1$.

Accessed 2 Nov 2020.

29. Kaltiala-Heino R, Fröjd S, Marttunen M. Sexual harassment and emotional and behavioural symptoms in adolescence: stronger associations among boys than girls. Soc Psychiatry Psychiatr Epidemiol. 2016;51(8):1193-201.
30. Anderson J. The impact of family structure on the health of children: efects of divorce. Linacre Q. 2014;81(4):378-87.

31. Koivusilta L, Honkala S, Honkala E, Rimpelä A. Toothbrushing as part of the adolescent lifestyle predicts education level. J Dent Res. 2003;82(5):3616.

32. Maes L, Maser M, Honkala S. Oral health. In: Currie $\mathrm{C}$ et al, editor. Young people's health in context. Health Behaviour in School-aged Children (HBSC) study: international report from the 2001/2002 survey. World Health Organization Regional Ofce for Europe 2004. http://www.euro.who.int/_data /assets/pdf_fle/0008/110231/e82923.pdf. Accessed 2 Nov 2020.

33. Savolainen J, Suominen-Taipale A, Uutela A, Aromaa A, Härkänen T, Knuuttila M. Sense of coherence associates with oral and general health behaviours. Community Dent Health. 2009;26 (4): 197-203.

34. Gomes AC, Rebelo MAB, de Queiroz AC, de Queiroz Herkrath APC, Herkrath FJ, Rebelo Vieira JM, et al.Socioeconomic status, social support, oral health beliefs, psychosocial factors, health behaviours and health-related quality of life in adolescents. Qual Life Res. 2020;29(1):141-51.

35. Padilla-Moledo C, Ruiz JR, Castro-Piñero J. Parental educational level and psychological positive health and health complaints in Spanish children and adolescents. Child Care Health Dev. 2016;42(4):534 43.

36. Whitehead R, Currie D, Inchley J, Currie C. Educational expectations and adolescent health behaviour: an evolutionary approach. Int J Public Health. 2015;60(5):599-608.

37. Bright MA, Alford SM, Hinojosa MS, Knapp C, Fernandez-Baca DE. Adverse childhood experiences and dental health in children and adolescents. Community Dent Oral Epidemiol. 2015;43(3):193-9.

38. Scrine C, Durey A, Slack-Smith L. Providing oral care for adults with mental health disorders: dental professionals' perceptions and experiences in Perth, Western Australia. Community Dent Oral Epidemiol. 2019;47(1):78-84.

39. Austregésilo SC, de Goes PSA, de Sena Júnior MR, Pazos CTC. Clustering of oral and general health risk behaviors among adolescents. Prev Med Rep. 2019;15:100936.

40. Tanner $T$, Päkkilä J, Karjalainen K, Kämppi A, Järvelin MR, Patinen P, et al. Smoking, alcohol use, socioeconomic background and oral health among young Finnish adult. Community Dent Oral Epidemiol. 2015;43(5):406-14.

41. Kobayashi D, Takahashi O, Shimbo T. Frequency of daily tooth brushing and development of any type of malignancy. Anticancer Res. 2019; 39(8):4415-21. 